\title{
LIQUID-LIQUID PHASE SEPARATION IN CONCENTRATED POLYMER SOLUTIONS STUDIED BY ELECTRON MICROSCOPY
}

\author{
P. T. van Emmerik and C. A. Smolders \\ Twente University of Technology, Enschede, The Netherlands \\ and \\ W. Geymayer \\ Technische Hochschule, Zentrum für Elektronenmikroskopie, Graz, Austria
}

(Received 19 October 1972)

\begin{abstract}
Depending upon quenching temperature and composition, liquid-liquid phase separation in polymer solutions will occur either by nucleation and growth or by the spinodal decomposition. Both mechanisms occur in the system poly(2,6-dimethyl-1,4-phenylene oxide)-toluene and can be made visible by electronmicroscopy using the freeze-etching method as sample preparation technique.
\end{abstract}

\section{INTRODUCTION}

LIQUID-LIQUID phase separation in homogeneous solutions will in principle proceed either by nucleation and growth or by the spinodal decomposition. ${ }^{(1)}$ Which of these mechanisms will be followed depends on quenching temperature and solution concentration and on the rate of cooling. The initial structures connected with these mechanisms can be characterized as follows: in the first case, nuclei will be formed and will grow until equilibrium is reached, ${ }^{(2)}$ in the second case interconnected structures can be formed. (1)

In both cases these primary structures can be destroyed by after-effects like coalescence.

The morphological changes during these phase separations have been widely investigated for many liquids ${ }^{(3-5)}$ but they could be observed in inorganic glassforming solutions only. ${ }^{(6)}$ For these systems, low angle X-ray studies ${ }^{(7)}$ have supported the concept of spinodal decomposition. However, direct observation of the onset of the demixing process with other than inorganic glass-forming systems have not yet been performed, due to experimental difficulties in preparing suitable replicas which can be studied by electron microscopy.

Recently in PPO*-caprolactam and in PPO-toluene solutions, the mechanism of liquid-liquid phase separation has been studied using light scattering methods ${ }^{(8)}$ and normal microscopy. ${ }^{(9,10)}$

The purpose of the present work was to study the first stages of phase separation in PPO-solutions, using the freeze etching method to obtain suitable replicas for electronmicroscopy.

* PPO refers to poly(2,6-dimethyl-1,4-phenylene oxide). 


\section{THE FREEZE-ETCHING METHOD}

In 1957 the freeze-etching method was introduced for the study of biological materials. ${ }^{(11)}$ The purpose of this method was to cool a sample of biological material extremely rapidly in order to prevent damage to the structure by crystallization of water. By etching away the ice fraction at low temperature $\left(-100^{\circ} \mathrm{C}\right)$ in high vacuum, the structure of the material was made visible through replica technique and electron microscopy.

In our studies the same procedure has been followed to study the onset of liquidliquid phase separation of PPO-solutions. A schematic view of sample treatment is presented in Fig. 1.

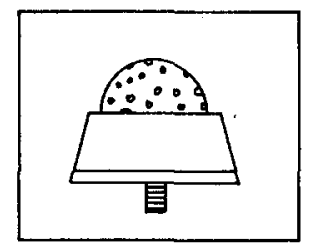

I

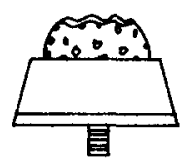

III

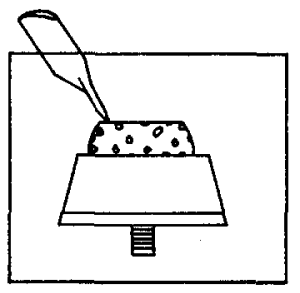

II

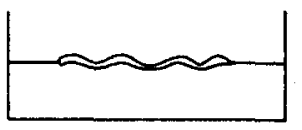

IV

FIG. 1. Schematic view of the freeze etching method. I. Quenching the sample in the sample holder in liquid nitrogen. II. Cutting the sample under liquid nitrogen to clear the inner structure. III. Etching and the preparation of the replica in vacuum. IV. Chemical separation of the replica.

\section{PRELIMINARY RESULTS FOR THE SYSTEM PPO-CAPROLACTAM}

Light scattering measurements performed with PPO-caprolactam ${ }^{(8)}$ solutions could be explained by accepting a spinodal decomposition mechanism during liquid-liquid phase separation.

Observations made under the light microscope supported the occurrence of this mechanism, which was further studied in 1968 in Graz with electron microscopy using the freeze-etching method. Some results are shown in Fig. $2 a$ to d. Figure $2 a$ shows a 10 per cent by weight PPO-caprolactam solution, which had been made homogeneous by heating to $160^{\circ} \mathrm{C}$ and subsequently quenched in liquid nitrogen. The rate of cooling is so large that the solution will transform into the glassy state without phase separation occurring. If a homogeneous solution was kept at $90^{\circ} \mathrm{C}$ for 60 seconds before quenching in liquid $\mathrm{N}_{2}$, a regular structure (believed to be the spinodal pattern) was observed (Fig. 2b). 


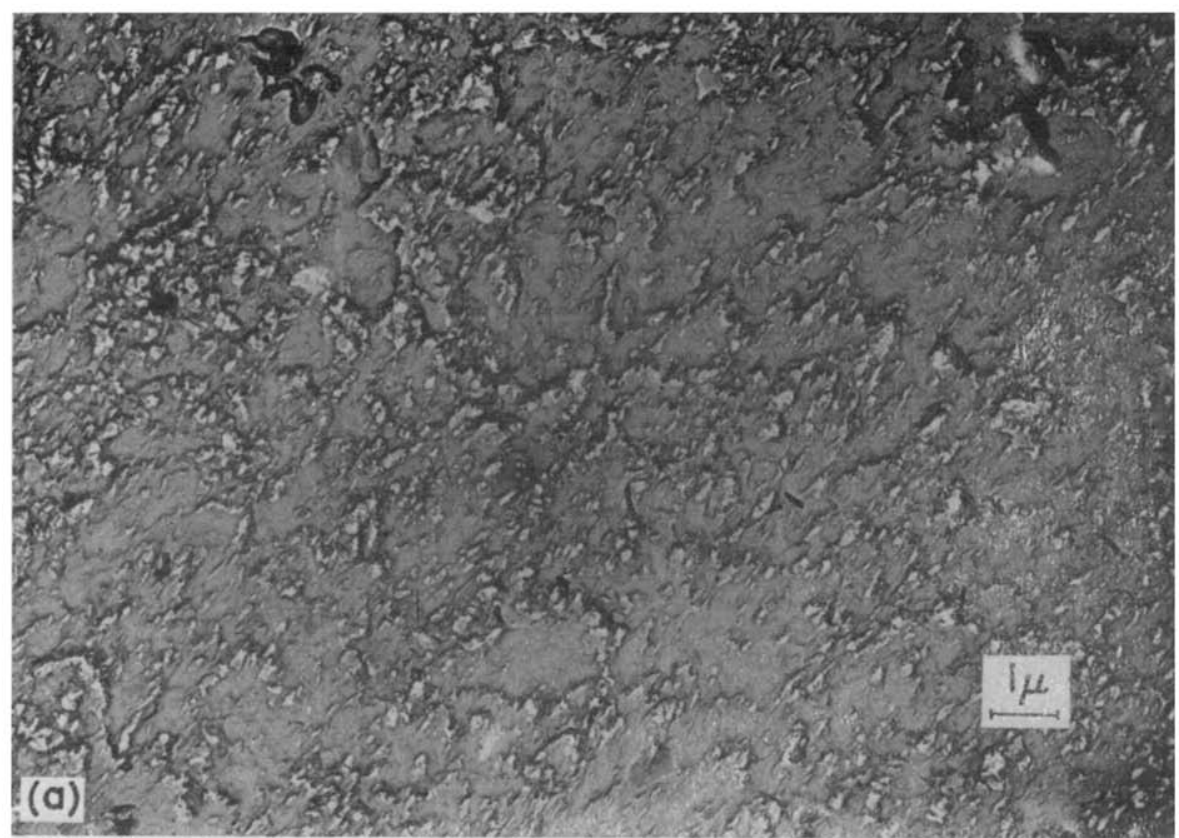

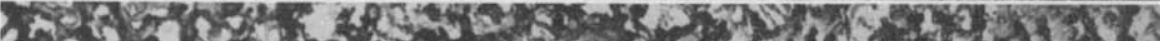

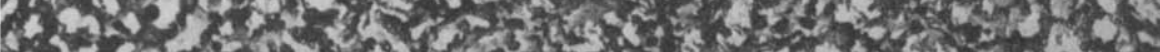

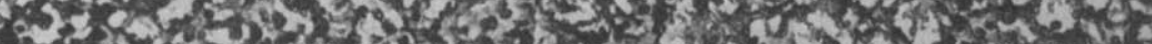

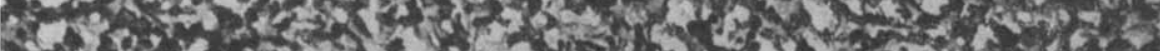

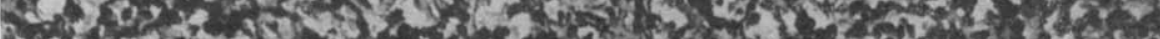

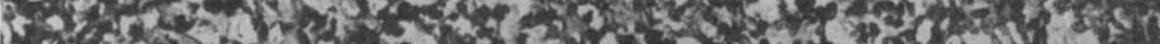

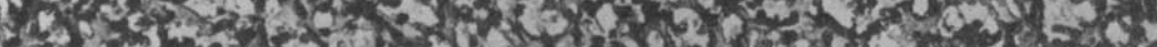

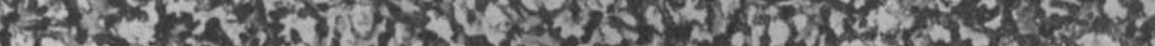

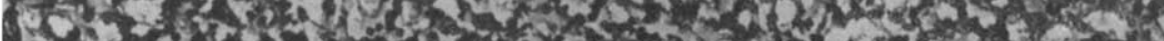

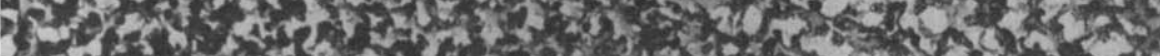

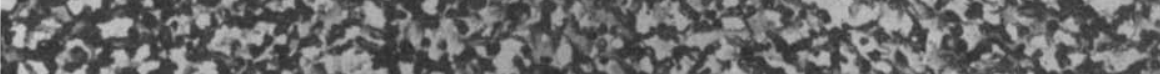

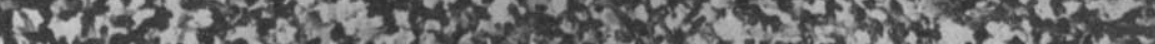

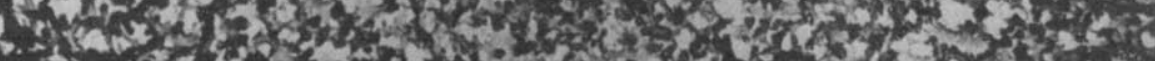

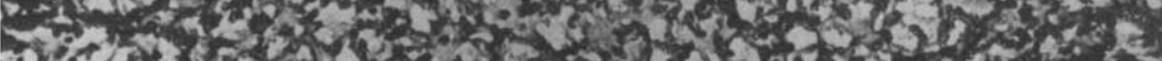

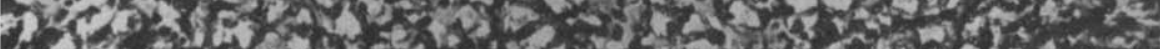

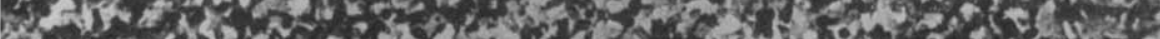

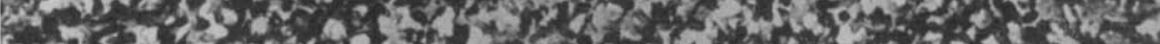

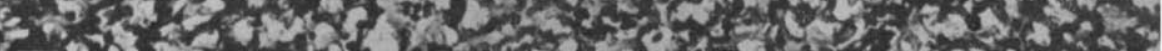

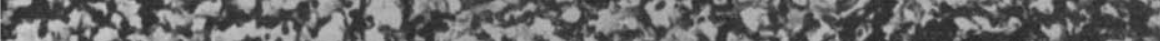

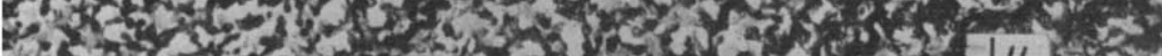

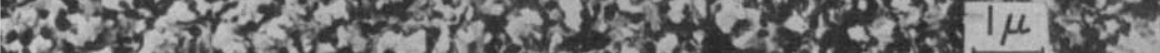

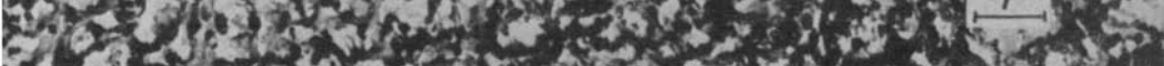

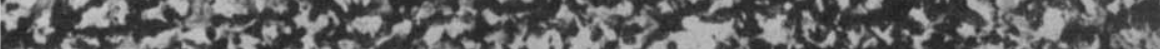

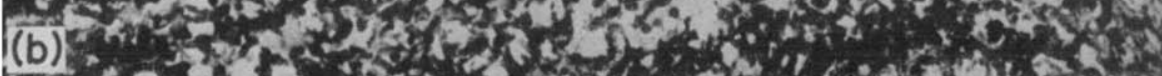

Figs. 2a \& 2b. 

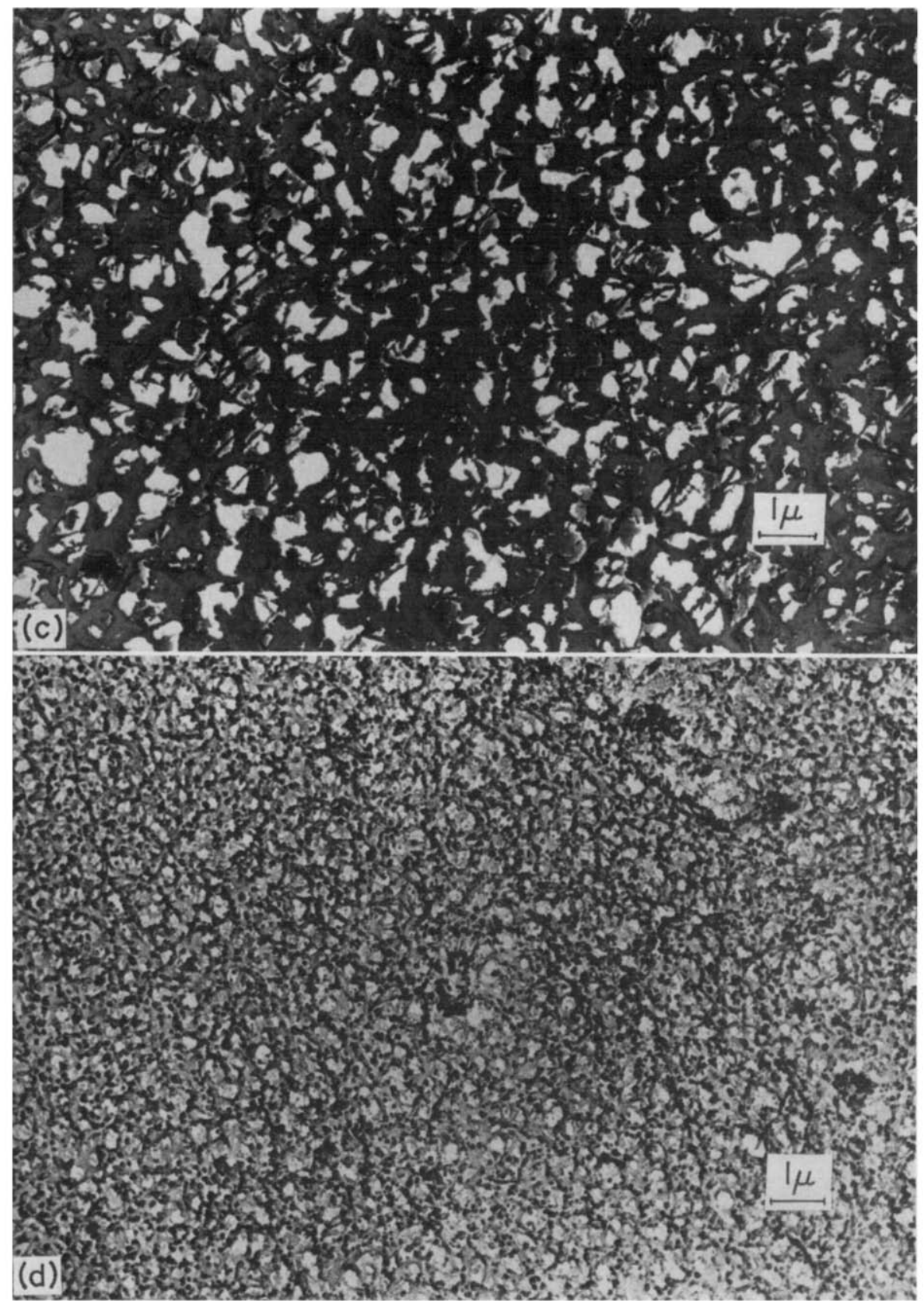

FIGs. $2 \mathrm{c} \& 2 \mathrm{~d}$.

FIG. 2. Poly(2,6-dimethyl-1,4-phenylene oxide) (10 per cent) in caprolactam. (a) Quenched directly in liquid nitrogen. (b) Quenched $60 \mathrm{sec}$ at $90^{\circ} \mathrm{C}$, thereafter in liquid nitrogen. (c) Quenched $30 \mathrm{sec}$ at $90^{\circ} \mathrm{C}$, therafter in liquid nitrogen. (d) Quenched $10 \mathrm{~min}$ at $120^{\circ} \mathrm{C}$, thereafter in liquid nitrogen. 

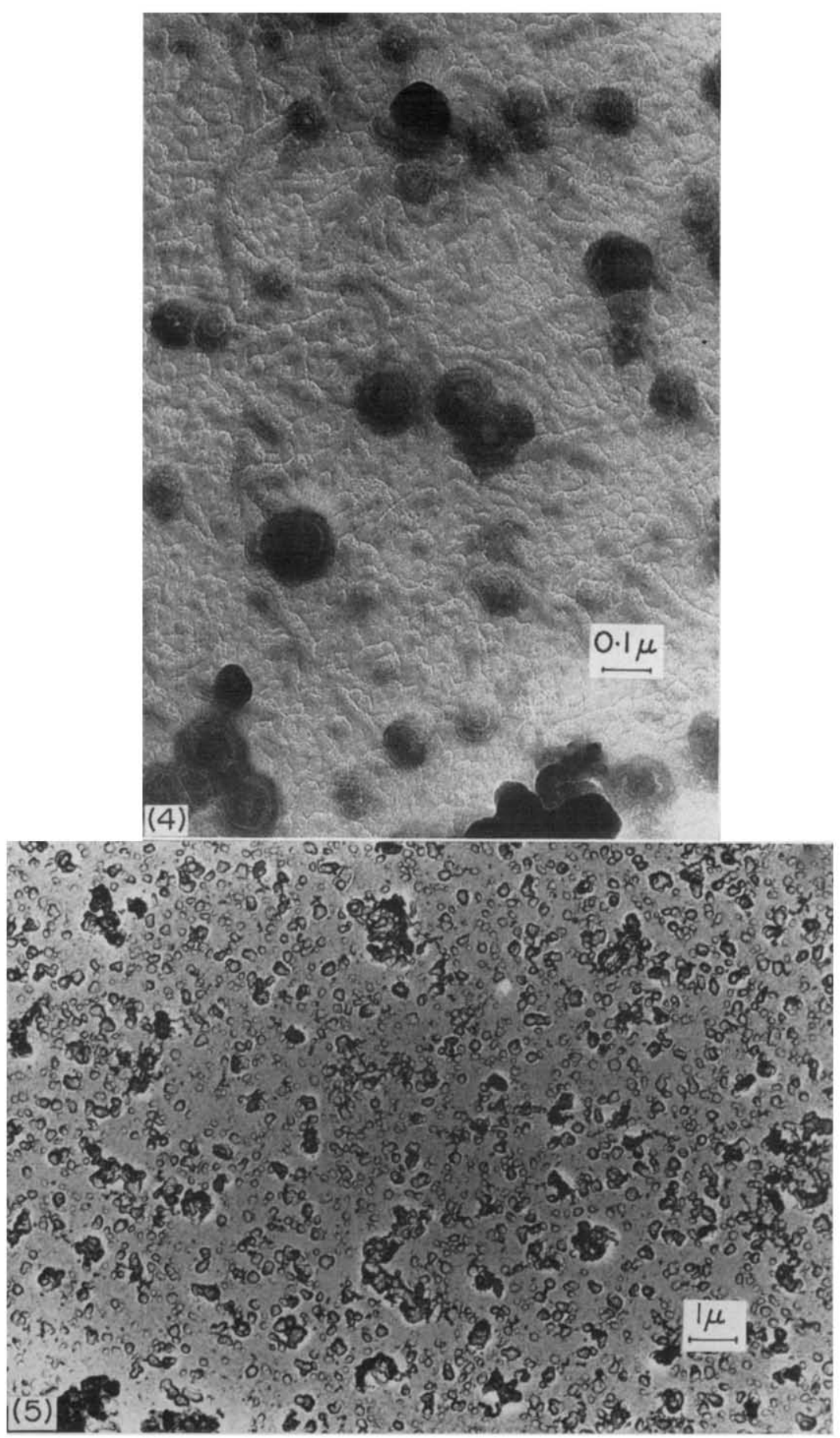

FIG. 4. Liquid-liquid phase separation by nucleation and growth of a 30 per cent by weight poly (2,6-dimethyl-1,4-phenylene oxide)-toluene solution quenched at $53^{\circ} \mathrm{C}$.

$$
T_{\text {cloudpt. }}=60^{\circ} \mathrm{C} ; T_{\text {spinodal }}=38^{\circ} \mathrm{C} ; \tau=100 \mathrm{~min} \text {. }
$$

FIG. 5. Liquid-liquid phase separation of a 30 per cent by weight poly(2,6-dimethyl-1,4phenylene oxide)-toluene solution quenched at a temperature $\left(T=40^{\circ} \mathrm{C}\right)$ just above the spinodal. 


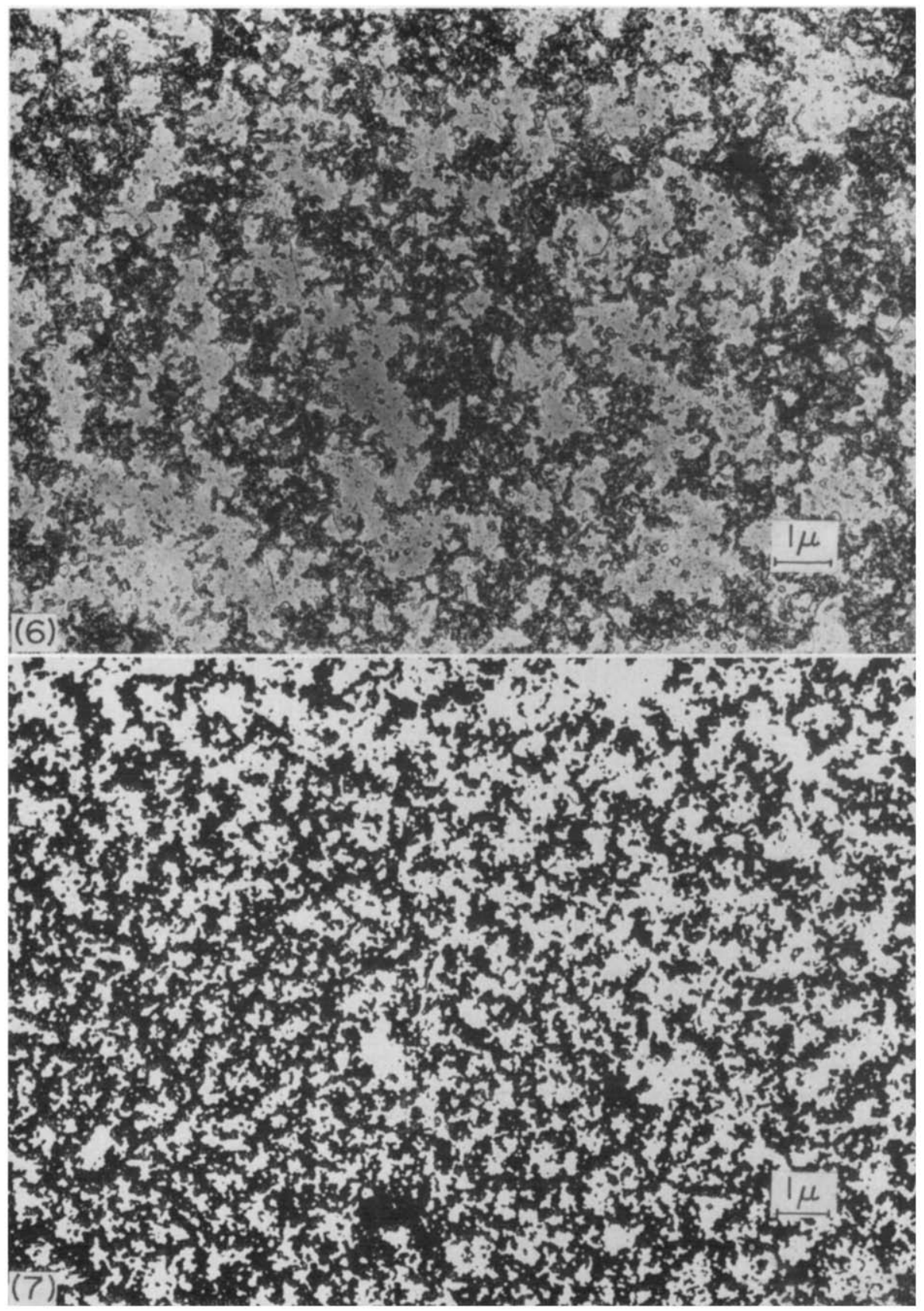

FIG. 6. Spinodal decomposition of a 30 per cent poly(2,6-dimethyl-1,4-phenylene oxide)toluene solution quenched at $T=0^{\circ} \mathrm{C}$.

FIG. 7. Spinodal decomposition patterns of a 30 per cent by weight poly(2,6-dimethyl-1,4phenylene oxide)-toluene solution quenched at $T=-15^{\circ} \mathrm{C}$. 
In Fig. $2 \mathrm{c}$ the result is shown of a homogeneous solution being cooled at $90^{\circ} \mathrm{C}$ for 30 seconds; this indicates that formation of nuclei at that temperature could not always be avoided. Upon quenching a PPO-caprolactam solution at higher temperatures, the spinodal pattern disappeared and numerous small nuclei were observed (Fig. 2d). Since thermodynamic data for the system PPO-caprolactam were unknown at that time, interpretation of these results was very difficult and could only be given qualitatively.

The system PPO-toluene shows the same phase separation behaviour as PPOcaprolactam..$^{(9,10)}$

For PPO-toluene the cloudpoint curve has been measured and a rather accurate estimate for the position of the spinodal could be given; ; $^{(9)}$ this made it worthwhile to study the onset of liquid-liquid phase separation by electron-microscopy more thoroughly.

\section{MORPHOLOGICAL CHARACTERISTICS}

In liquid-liquid phase separation, the formation and growth of stable concentration fluctuations of limited size has been the subject of nucleation theory. ${ }^{(12,13)}$

The result of this mechanism will be the formation of numerous small droplets of one of the equilibrium phases. Growth of these droplets, coalescence and ageing phenomena can eventually lead to two bulk liquid phases. If the liquid is very viscous and the growth of nuclei is slow, the separation process can be stopped at any time by rapid cooling and an investigation of the critical size of nuclei is possible.

In the spinodal decomposition mechanism, the solution is unstable with respect to infinitesimal concentration fluctuations and the only barrier to separation is diffusion. The kinetics of this type of phase change have been extensively discussed by Cahn ${ }^{(14,15)}$ According to this theory, the decomposition process is initiated by a rapid growth of certain components of composition fluctuations, and fluctuations with a certain wave number, $\beta_{m}$, will show maximum growth rate. The selective amplification of these spatial components may result in the formation of a periodic, mosaic-like texture. By comparison between theories for critical opalescence and spinodal decomposition, the dimension most frequently realized in early stages of phase separation in polymer solutions has been given by ${ }^{(16)}$

$$
D_{m}=2 \pi \beta_{m}^{-1}=2 \pi l\left[3\left(1-T / T_{s}\right)\right]^{-\frac{1}{2}}
$$

$l=$ range of molecular interaction; $T=$ phase separation temperature $\left(T<T_{s}\right)$; $T_{s}=$ spinodal temperature.

If the concentrated phase to be separated during the demixing process is at least 15 per cent by volume, then interconnected structures will be formed as found before in several glass forming mixtures. ${ }^{(1)}$

\section{EXPERIMENTAL}

Homogeneous solutions of PPO-toluene were made by weighing appropriate amounts of the components in small glass tubes which were flushed with nitrogen and sealed under vacuum. After complete dissolution in a thermostat bath at $160^{\circ} \mathrm{C}$, the tubes were brought into a bath at the desired temperature for an appropriate time.

After breaking the tubes, part of the contents was carefully brought into a sample holder which was held at the same temperature on a heating stage. The sample and the sample holder were then quenched in liquid nitrogen to stop the phase separation process. 
After cutting at $-196^{\circ} \mathrm{C}$, the sample was brought in the freeze etching apparatus(EPA 100, Leybold) where freeze etching took place at $-196^{\circ} \mathrm{C}$ and a pressure of $\approx 10^{-6}$ torr for periods between 15 and 90 minutes. A carbon replica was prepared in the normal way; at the end of the procedure, it was separated from the sample by dissolving the latter in chloroform at room temperature. The replica was deposited upon a grid and studied with transmission electron microscopy.

\section{RESULTS AND DISCUSSION}

In the system PPO-toluene three phase separation curves can be detected, viz. the melting point curve, the cloudpoint curve and the spinodal. ${ }^{(9)}$ If a homogeneous PPO-toluene solution is cooled, liquid-liquid phase separation always precedes the crystallization, the latter taking place only in the concentrated polymer phase.

Homogeneous solutions cooled at the appropriate temperature, between the cloudpoint curve and the spinodal, demix by the nucleation and growth mechanisms. As a typical feature of this system, nucleation occurs after a certain induction time $\tau$ which approaches zero at temperatures close to the spinodal.

For solutions up to $50 \%$ by weight PPO in toluene, the induction times have been determined at different temperatures. For each concentration, the plot of $\ln \tau$ vs $1 / T$ was linear over the temperature range between cloudpoint curve and spinodal curve (Fig. 3). Consequently the induction times at each temperature are known and

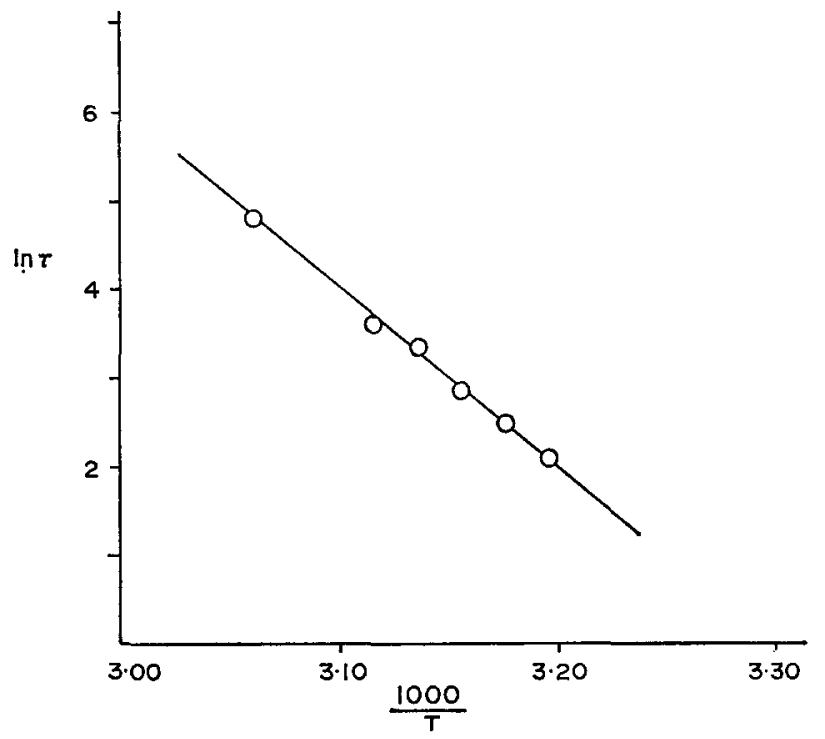

FIG. 3. $\ln \tau$ vs $1000 / T ; \tau$ is the induction time in minutes of a 30 per cent by weight poly(2,6-dimethyl-1,4-phenylene oxide)-toluene solution as a function of temperature expressed in $\operatorname{deg} \mathbf{K}$.

the demixing process could be stopped by rapid cooling at times below or above the induction time $\tau$. Thus solutions could be studied in which nuclei were not yet formed, had just been formed and at later stages of the demixing process. In solutions kept at an appropriate demixing temperature for a time $t<\tau$, neither regular structures nor nuclei could be detected, indicating that for this system indeed a definite time is required before nucleation starts. 
The results for a system where nuclei had just been formed are shown in Fig. 4.

Measurements of the growth rate of nuclei with the light microscope indicate that a reasonable estimate of the growth rate at that particular temperature for a 30 per cent by weight solution is

$$
\frac{\mathrm{d} r}{\mathrm{~d} t}=0 \cdot 15 \mu \mathrm{m} \min ^{-1}
$$

where $r$ is the radius of the nucleus at time $t$.

Since quenching takes place in about $0.5 \mathrm{sec}$, the nucleus can grow at most $10-20 \AA$ during the quenching time. Hence the nuclei thus detected must be of about critical size.

In those cases where homogeneous mixtures of PPO-toluene are cooled at temperatures below the spinodal, two phenomena have been observed.

1. At final quenching temperatures not greatly different from the spinodal temperature, many nuclei are formed while passing the metastable area. Cooling to a temperature just above the spinodal gives the patterns of Fig. 5 . Hence it is clear that the speed of passing the metastable region determines the structure in the liquid mixture.*

The spinodal structure obtained when cooling to a temperature not far below $T_{\text {spinodal }}$, is shown in Fig. 6 . The interconnected concentrated areas are built up of numerous very small nuclei which may contain also crystallization effects.

2. If homogeneous solutions were quenched at temperatures far below the spinodal, the metastable region was passed quickly and, apart from a few nuclei, interconnected structures were formed. This is shown in Fig. 7 where the concentrated areas have been printed equally black by photographic means in order to make a crude estimate of the spinodal dimension $D_{m}$. By using Eqn. (1), taking $l=200 \AA$ and $T_{s}=311 \mathrm{~K}$, the characteristic dimensions of the spinodal wavelength for a 30 per cent by weight PPO-toluene solution can be calculated. At $T=258 \mathrm{~K}$, $D_{m \text {,calc. }}=0.16 \mu$; the experimental values as determined by electron microscopy are of the same order of magnitude.

\section{CONCLUSIONS}

The freeze etching method offers a possibility of making visible the onset of liquidliquid phase separation in certain polymer-solvent systems. However, one should be aware of the artefacts which could be introduced by this method. The structure made visible by the electron microscope may be affected by the speed of cooling of the sample to the appropriate temperature, the speed of quenching to liquid nitrogen temperature and the thickness of the carbon replica, which may vary between 200 and $500 \AA$. Therefore the results can only be evaluated in a qualitative way.

* The irregular shapes of the droplets in Fig. 5 might be due to artefacts introduced during sample preparation, or might be caused by crystallization of these concentrated areas. ${ }^{(9)}$

Differential scanning calorimetry ${ }^{(17)}$ has shown that after liquid-liquid phase separation has set in by either of the two mechanisms already mentioned, the concentrated phase will crystallize if kept at the quenching temperature for a certain time. 
The following conclusions can be drawn:

1. When liquid-liquid phase separation occurs in PPO-toluene solutions at temperatures between the cloud-point curve and the spinodal, an induction time elapses before nuclei are formed. This induction time becomes zero at temperatures close to the spinodal and reaches high values at temperatures near the cloudpoint.

2. The smallest nuclei that were detected had a radius of about $400 \AA$.

3. When homogeneous solutions are cooled at temperatures below the spinodal, interconnected structures are observed as predicted by theory.

Acknowledgements-Thanks are due to Mr. L. Broens for doing much experimental work and to Mr. J. C. Lodder for making the electron microscope photographs.

\section{REFERENCES}

(1) J. W. Cahn, J. chem. Phys. 42, 93 (1965).

(2) M. Volmer and A. Weber, Z. Phys. Chem. 119, 277 (1926).

(3) C. A. Smolders, J. J. van Aartsen, A. Steenbergen, Kolloid-Z.u.Z. Polymere 243, 14 (1971).

(4) A. E. Nielsen and S. Sarig, J. Cryst. Growth 8, 1 (1971).

(5) B. E. Sundquist and R. A. Oriani, J. chem. Phys. 16, 2604 (1962).

(6) J. J. Hammel, J. chem. Phys. 46, 2234 (1967).

(7) J. Zarzycki and F. Naudin, J. Non. Cryst. Solids 1, 3 (1969).

(8) J. J. van Aartsen and C. A. Smolders, Europ. Polym. J. 6, 105 (1970).

(9) P. T. van Emmerik and C. A. Smolders, Proc. 8th Prague Microsymp. J. Polym. Sci. C38 73 (1972).

(10) P. T. van Emmerik and C. A. Smolders, Proc. 9th Prague Microsymp. J. Polym. Sci. C39 311 (1972).

(11) R. L. Steere, J. Biophys. biochem. Cyt. 3, 45 (1957); W. Geymayer and F. Grasenich, Kongress für Elektronenmikroskopie, Aachen (1965).

(12) J. W. Gibbs, Collected Work, Vol I, p. 105. Yale Univ. Press (1948).

(13) D. Turnbull and J. C. Fisher, J. chem. Phys. 17, 71 (1949).

(14) J. W. Cahn and J. E. Hilliard, J. chem. Phys. 31, 688 (1959).

(15) J. W. Cahn, Trans. A.J.M.E. 242, 167 (1968).

16) J. J. van Aartsen Europ. Polym. J. 6, 919 (1970).

17) P. T. van Emmerik and C. A. Smolders, Europ. Polym. J. 9, 293 (1973).

Résumé-La séparation de phase liquide-liquide de solutions de polymère, qui dépend de la température de trempe et de la composition apparaîtra soit par germination et croissance soit par décomposition "spinodale".

Les deux mécanismes apparaissent dans le système poly(diméthyl 2,6 oxyde de phénylène 1,4)toluène. La microscopie électrotronique permet de les visualiser en méthode d'attaque par congélation comme technique de préparation de l'échantillon.

Sommario-A seconda della temperature di spegnimento e della composizione, la separazione di fase liquido-liquido nelle soluzioni di polimeri avviene sia per germinazione e accrescimento ovvero per scissione spinoidale. Entrambi i meccanismi si verificano nel sistema poli(2,6-dimetil-1,4-fenilene ossido)-toluene e possono essere resi visibili mediante microscopio elettronico e tecnica di preparazione detta "attacco chimico-congelamento".

Zusammenfassung-Die Trennung von Polymerlösungen in zwei flüssige Phasen erfolgt je nach Grad der Unterkühlung und Zusammensetzung durch Keimbildung und Wachstum oder durch spinodale Zersetzung. In dem System Poly(2,6 dimethyl 1,4 phenylenoxid)-Toluol treten beide Mechanismen auf und können im Elektronenmikroskop durch Gefrierätzung sichtbar gemacht werden. 